\title{
Laryngopharyngeal dysfunction after the Norwood procedure
}

\author{
Margaret L. Skinner, MD, ${ }^{a}$ Lucinda A. Halstead, MD, ${ }^{a}$ Catherine S. Rubinstein, MSN, FNP, ${ }^{b}$ Andrew M. Atz, MD, \\ Diane Andrews, SLP, and Scott M. Bradley, MD
}

From the Evelyn Trammell Institute of Voice and Swallowing, Department of Otolaryngology-Head and Neck Surgery, ${ }^{\mathrm{a}}$ and the Divisions of Cardiothoracic Surgery $^{\mathrm{b}}$ and Pediatric Cardiology, ${ }^{\mathrm{c}}$ Medical University of South Carolina, Charleston, SC.

Read at the Eighty-fifth Annual Meeting of The American Association for Thoracic Surgery, San Francisco, Calif, April 10-13, 2005.

Received for publication April 8, 2005; revisions received June 6, 2005; accepted for publication June 8, 2005.

Address for reprints: Scott M. Bradley, MD, Division of Cardiothoracic Surgery, Medical University of South Carolina, 96 Jonathan Lucas St, Charleston, SC 29425 (E-mail bradlesm@musc.edu).

J Thorac Cardiovasc Surg 2005;130:1293-301 $0022-5223 / \$ 30.00$

Copyright (C) 2005 by The American Association for Thoracic Surgery

doi:10.1016/j.jtcvs.2005.07.013
Objective: We sought to evaluate the incidence and significance of recurrent laryngeal nerve and swallowing dysfunction after a Norwood procedure compared with that after biventricular aortic arch reconstruction.

Methods: From April 2003 through December 2004, 36 neonates underwent a Norwood procedure; 33 of 36 had postoperative fiberoptic laryngoscopy and modified barium swallow. Study results were used to guide the transition from nasogastric tube to oral feeding and placement of gastrostomy tubes. During the same time period, 18 neonates underwent aortic arch reconstruction as part of a biventricular repair.

Results: After a Norwood procedure, laryngoscopy showed left true vocal fold (cord) paralysis in 3 (9\%) of 33 patients. The results of a modified barium swallow were abnormal in 16 (48\%) of 33 patients, with aspiration in 8 (24\%) of 33 patients. Of the 3 patients with vocal fold paralysis, 2 had a normal modified barium swallow result, and 1 had aspiration. Gastrostomy tubes were placed in $6(18 \%)$ of 33 patients, all with an abnormal modified barium swallow result. Hospital stay was longer in patients with an abnormal modified barium swallow result: $34 \pm 13$ versus $22 \pm 7$ days $(P<.01)$. After biventricular repair with aortic arch reconstruction, left true vocal fold paralysis occurred in $4(25 \%)$ of 16 patients; results of a modified barium swallow were abnormal in $10(59 \%)$ of 17 patients, with aspiration in 6 (35\%) of 17 patients (all nonsignificant vs patients undergoing the Norwood procedure). Follow-up laryngoscopy in 4 patients with vocal fold paralysis showed no change in 3 of 4 patients and improvement in 1 patient. Follow-up modified barium swallow showed resolution of aspiration in $11(85 \%)$ of 13 patients. Hospital survival was $32(89 \%)$ of 36 patients for the Norwood procedure and $18(100 \%)$ of 18 patients for biventricular repair. There has been 1 sudden death before secondstage palliation.

Conclusions: After a Norwood procedure, swallowing dysfunction occurs in $48 \%$ of patients, with aspiration in $24 \%$, and results in increased length of hospital stay. Left recurrent laryngeal nerve injury, seen in $9 \%$ of patients, is an uncommon cause of swallowing dysfunction. Postoperative aspiration generally resolves over time, whereas vocal fold paralysis does not. Systematic evaluation of swallowing function allows appropriate tailoring of feeding regimens and might contribute to decreased hospital and interstage mortality.

$\mathrm{T}$ he Norwood procedure is widely used to palliate neonates with a functional single ventricle and systemic outflow tract obstruction, such as hypoplastic left heart syndrome. As operative survival has improved, ${ }^{1-7}$ it has become increasingly important to examine other measures of outcome after surgical intervention. Feeding intolerance can be a significant source of morbidity after a Norwood procedure. It can prolong hospital stay and has been implicated in interstage death 


\section{Abbreviations and Acronyms \\ MBS $=$ modified barium swallow \\ VSD $=$ ventricular septal defect}

between hospital discharge and second-stage palliation. The Norwood procedure, as well as other operations on the aortic arch, involves mobilization of the recurrent laryngeal nerve. Operative damage to the nerve is one potential source of postoperative swallowing dysfunction. ${ }^{8,9}$ However, little information is available on either swallowing function or recurrent laryngeal nerve function after a Norwood procedure.

The aim of this study is to evaluate the incidence and significance of recurrent laryngeal nerve and swallowing dysfunction after the Norwood procedure. Recurrent nerve function has been evaluated by means of fiberoptic laryngoscopy, and swallowing function has been evaluated with modified barium swallow (MBS). The findings in patients who have undergone a Norwood procedure are compared with those in neonates undergoing aortic arch reconstructions as part of a biventricular repair.

\section{Methods}

\section{Patient Demographics}

This study was approved by the Institutional Review Board of the Medical University of South Carolina. From April 2003 through December 2004, 36 neonates underwent a Norwood procedure. Diagnoses were hypoplastic left heart syndrome in 34 patients and single left ventricle with aortic arch hypoplasia in 2 patients. Thirty-three (92\%) of the 36 had fiberoptic laryngoscopy and MBS carried out in the postoperative period and are included in this study. The remaining 3 patients died without undergoing evaluation. One study patient died before discharge; overall hospital survival was 32 (89\%) of 36 patients.

During the same time period, 18 neonates underwent aortic arch reconstruction through a median sternotomy as part of a biventricular repair. Diagnoses were aortic coarctation with ventricular septal defect (VSD) in 10 patients, interrupted aortic arch with VSD in 7 patients, and coarctation with transposition of the great arteries and multiple VSDs in 1 patient. Sixteen (89\%) of the 18 patients had laryngoscopy and 17 (94\%) of the 18 patients had MBS carried out in the postoperative period. There were no deaths among the 18 patients undergoing biventricular repair. All operations were performed by a single surgeon (S.M.B.).

\section{Operative Approach}

Among the 33 patients undergoing the Norwood procedure in the study, operations were carried out at a median age of 6 days (range, 2-19 days) and a median weight of $3.1 \mathrm{~kg}$ (range, 1.9-4.2 $\mathrm{kg}$ ). The operative approach included pulmonary homograft reconstruction of the neoaorta in all patients. Dissection routinely included the ductus arteriosus and descending aorta beyond any potential coarctation site. Dissection was carried out by using blunt dissection immediately adjacent to the vessel adventitia. The recurrent laryngeal nerve was visualized and mobilized away from the ductus and aorta with surrounding connective tissue. Operations included a right ventricle-to-pulmonary artery shunt in 27 patients and a modified Blalock-Taussig shunt in 6 patients. Regional low-flow perfusion of the innominate artery was used in 31 (94\%) of 33 patients. ${ }^{10}$ The mean operative support time (cardiopulmonary bypass plus circulatory arrest) was $186 \pm 30$ minutes, the mean myocardial ischemic time was $54 \pm 9$ minutes, and the mean circulatory arrest time was $12 \pm 12$ minutes.

Among the 18 patients undergoing biventricular repair in the study, operations were carried out at a median age of 9 days (range, 4-33 days) and a median weight of $3.1 \mathrm{~kg}$ (range, 2.0-3.7 $\mathrm{kg}$ ). The operative approach included primary arch reconstruction in all patients. Regional low-flow perfusion of the innominate artery was used in all patients. The mean operative support time (cardiopulmonary bypass plus circulatory arrest) was $169 \pm 42$ minutes, the mean myocardial ischemic time was $73 \pm 18$ minutes, and the mean circulatory arrest time was $6 \pm 12$ minutes. Transesophageal echocardiography was not used in any patient undergoing either the Norwood procedure or biventricular repair.

\section{Laryngopharyngeal Evaluation}

Fiberoptic laryngoscopy was performed by a single otolaryngologist (L.A.H.). An Olympus ENF P4 fiberoptic laryngoscope Olympus, Tokyo, Japan was passed transorally, transnasally, or both, depending on the ability to visualize the glottis and the patient's gag reflex. Topical nasal anesthetics were not used. On rare occasions, oxymetazoline $\mathrm{HCl}$ was used as a nasal decongestant. The initial laryngeal examination was generally performed in the pediatric cardiac intensive care unit. When feasible, subsequent examinations with video recording were performed in the Medical University of South Carolina Evelyn Trammell Institute for Voice and Swallowing. The character of the infant's cry (strong or weak), presence or absence of stridor, vocal fold (cord) mobility, and general appearance of the larynx were assessed at each laryngoscopy. Vocal fold paresis was defined as impaired or incomplete abduction and adduction of the vocal fold. Vocal fold paralysis was defined as complete immobility of the vocal fold. A glottic gap was considered to be present when both vocal folds were mobile but adducted incompletely, leaving a space of $1 \mathrm{~mm}$ to several millimeters between the vocal folds. Vocal fold dyskinesia described paradoxical motion of the bilateral vocal folds, with adduction during inspiration, rather than slight abduction, which is physiologic.

MBSs were carried out in the pediatric radiology suite, with a pediatric radiologist and speech-language pathologist present. All studies were reviewed by a single speech-language pathologist (D.A.) and were analyzed with respect to the oral (suckling) and pharyngeal phases of swallow. MBS studies followed a standardized protocol. The patient was positioned at $70^{\circ}$, and the swallowing was viewed in the lateral plane. At the initial study, the patient was presented with 5 swallows of liquid barium of 2 consistencies: thick and thin. Thin liquid barium was made by mixing thick liquid barium with sterile water in a 50/50 ratio. Laryngeal penetration was considered present if the bolus entered the glottic aperture but was ejected and did not pass the level of the vocal folds. Aspiration was considered present if the bolus entered the glottic aperture and passed below the level of the vocal folds into the subglottis and trachea. If aspiration was present, nasogastric tube feeding was continued until a repeat MBS showed resolution. Repeat studies 
TABLE 1. Laryngopharyngeal function in patients after a Norwood procedure

\begin{tabular}{|c|c|c|c|c|c|c|}
\hline \multirow[b]{2}{*}{ Patient no. } & \multirow[b]{2}{*}{ Direct laryngoscopy } & \multicolumn{4}{|c|}{ Modified barium swallow } & \multirow[b]{2}{*}{ G-tube } \\
\hline & & Normal & Aspiration & Suck & Swallow & \\
\hline 1 & Left TVF paralysis & - & Yes & - & Delayed & - \\
\hline 2 & Glottic gap & - & Yes & - & Poor coordination & Yes \\
\hline 3 & - & - & Yes & Absent & - & Yes \\
\hline 4 & - & Yes & - & - & - & - \\
\hline 5 & - & - & - & Poor & - & - \\
\hline 6 & - & - & Yes & - & - & - \\
\hline 7 & - & Yes & - & - & - & - \\
\hline 8 & - & - & - & Absent & - & Yes \\
\hline 9 & - & - & - & Poor & Laryngeal penetration & - \\
\hline 10 & - & - & - & Absent & - & Yes \\
\hline 11 & - & - & - & Poor & - & Yes \\
\hline 12 & Glottic gap & - & Yes & Poor & - & Yes \\
\hline 13 & - & Yes & - & - & - & - \\
\hline 14 & - & - & Yes & - & - & - \\
\hline 15 & - & Yes & - & - & - & - \\
\hline 16 & - & Yes & - & - & - & - \\
\hline 17 & - & Yes & - & - & - & - \\
\hline 18 & - & Yes & - & - & - & - \\
\hline 19 & - & Yes & - & - & - & - \\
\hline 20 & - & Yes & - & - & - & - \\
\hline 21 & - & Yes & - & - & - & - \\
\hline 22 & - & Yes & - & - & - & - \\
\hline 23 & Left TVF paralysis & Yes & - & - & - & - \\
\hline 24 & - & Yes & - & - & - & - \\
\hline 25 & - & Yes & - & - & - & - \\
\hline 26 & Edema & - & Yes & - & - & - \\
\hline 27 & Left TVF paralysis & Yes & - & - & - & - \\
\hline 28 & - & Yes & - & - & - & - \\
\hline 29 & Glottic gap & - & Yes & - & - & - \\
\hline 30 & - & - & - & - & Laryngeal penetration & - \\
\hline 31 & TVF dyskinesia & Yes & - & - & - & - \\
\hline 32 & - & - & - & - & Laryngeal penetration & - \\
\hline 33 & Granulations & - & - & - & Poor coordination & - \\
\hline
\end{tabular}

G-tube, Feeding gastrostomy tube; TVF, true vocal fold.

were also scheduled for patients with other abnormalities or in whom the initial study was limited by poor effort. MBS results were used to guide transition from nasogastric tube to oral feeding, need for thickened feedings, and placement of feeding gastrostomy tubes.

\section{Statistics}

Results are shown as means \pm standard deviation unless otherwise noted. Intergroup comparisons and evaluation of predictors of postoperative vocal cord paralysis and swallowing dysfunction were done by using the unpaired Student $t$ test, the Fisher exact test, or the $\chi^{2}$ test, as appropriate.

\section{Results}

\section{Norwood Procedure}

Fiberoptic laryngoscopy was carried out a median of 10 days (range, 4-27 days) after surgical intervention. Paralysis of the left true vocal fold was found in $3(9 \%)$ of 33 patients
(Table 1). Additional findings were a glottic gap in 3 patients, granulation tissue in 1 patient, glottic edema in 1 patient, and vocal fold dyskinesia in 1 patient. The initial postoperative MBS was carried out a median of 14 days (range, 6-84 days) after surgical intervention. In several cases the initial MBS was limited by patient effort, and swallowing abnormalities became apparent only on subsequent studies. An MBS result was abnormal in 16 (48\%) of 33 patients (Table 1). We documented aspiration in $8(24 \%)$ of 33 patients, poor or absent suck mechanism in 7 (21\%) of 33 patients, poor swallow coordination in $3(9 \%)$ of 33 patients, and laryngeal penetration in $3(9 \%)$ of 33 patients (Table 1).

Among the 3 patients with left true vocal fold paralysis, 2 had a normal MBS result, and 1 had delayed swallowing with aspiration (Table 1). All 3 patients with a glottic gap had aspiration demonstrated by MBS (Table 1). 
TABLE 2. Laryngopharyngeal function in patients after aortic arch reconstruction as part of a biventricular repair

\begin{tabular}{|c|c|c|c|c|c|c|}
\hline \multirow[b]{2}{*}{ Patient no. } & \multirow[b]{2}{*}{ Direct laryngoscopy } & \multicolumn{4}{|c|}{ Modified barium swallow } & \multirow[b]{2}{*}{ G-tube } \\
\hline & & Normal & Aspiration & Suck & Swallow & \\
\hline 1 & NA & Yes & - & - & - & - \\
\hline 2 & Left TVF paralysis & - & Yes & - & - & - \\
\hline 3 & - & Yes & - & - & - & - \\
\hline 4 & Left TVF paralysis & Yes & - & - & - & - \\
\hline 5 & - & Yes & - & - & - & - \\
\hline 6 & Left TVF paralysis & - & Yes & - & - & - \\
\hline 7 & - & - & - & - & Laryngeal penetration & - \\
\hline 8 & Left TVF paralysis & - & - & Poor & - & - \\
\hline 9 & - & - & Yes & - & - & - \\
\hline 10 & Granulations & - & - & - & Poor coordination & - \\
\hline 11 & TVF dyskinesia & - & - & - & Dysmotility & Yes \\
\hline 12 & - & Yes & - & - & - & - \\
\hline 13 & - & - & Yes & - & - & - \\
\hline 14 & - & Yes & - & - & - & - \\
\hline 15 & - & Yes & - & - & - & - \\
\hline 16 & - & - & Yes & - & Poor coordination & Yes \\
\hline 17 & - & - & Yes & - & - & - \\
\hline 18 & NA & NA & NA & NA & NA & - \\
\hline
\end{tabular}

G-tube, Feeding gastrostomy tube; NA, not available; TVF, true vocal fold.

The following variables were analyzed as predictors of laryngopharyngeal dysfunction: patient age, patient weight, genetic abnormality or syndrome, cardiopulmonary bypass time, circulatory arrest time, and duration of tracheal intubation. None was associated with either vocal fold paralysis or an abnormal MBS result. Patients with an abnormal MBS result had a longer mean intensive care unit stay $(18 \pm 12$ vs $12 \pm 5$ days, $P=.05$ ) and hospital stay ( $34 \pm 13$ vs 22 \pm 7 days, $P<.01)$.

Feeding gastrostomy tubes were placed in $6(18 \%)$ of 33 patients before hospital discharge (Table 1). All 6 had an abnormal MBS result, and none had vocal cord paralysis. Indications for gastrostomy tube placement were persistent aspiration in 3 patients (in association with a glottic gap in 2 patients) and persistent poor oral feeding in 3 patients. Concomitant Nissen fundoplication for gastroesophageal reflux was carried out in 2 patients, and the Ladd procedure for intestinal malrotation was performed in 1 patient.

Among the 33 patients undergoing the Norwood procedure in the study, 1 died before hospital discharge. This patient (no. 29, Table 1) had a prolonged hospitalization because of endocarditis, requiring reoperation to replace an infected right ventricle-to-pulmonary artery shunt with a modified Blalock-Taussig shunt. He had a glottic gap, as determined by means of laryngoscopy and aspiration on initial MBS. The results of subsequent MBS were normal, and oral feedings were initiated. He died of sudden hemodynamic deterioration 3 months after the operation. The remaining 32 patients were discharged, receiving formula or breast milk by mouth in 24 patients, thickened feedings by mouth in 2 patients, and gastrostomy feedings in 6 patients. There has been 1 sudden unexpected death after discharge. This patient (no. 14, Table 1) had a normal laryngoscopic result and aspiration on MBS. Subsequent MBS showed laryngeal penetration. He was discharged on oral feedings and died at 2 months of age of unclear causes.

At the time of second-stage palliation at $5.7 \pm 1.1$ months of age, the median weight of the patients undergoing the Norwood procedure was below the third percentile for age (range, 2nd-63rd percentile). There was no difference in the percentile weight of patients fed by mouth versus those fed by gastrostomy tube $(P=.7)$.

\section{Biventricular Repair}

After aortic arch reconstruction as part of a biventricular repair, postoperative fiberoptic laryngoscopy demonstrated paralysis of the left true vocal fold in 4 (25\%) of 16 patients (Table 2). The results of postoperative MBS were abnormal in $10(59 \%)$ of 17 patients, with aspiration in $6(35 \%)$ of 17 (Table 2). Among the 4 patients with vocal fold paralysis, 2 had aspiration by MBS (Table 2). Feeding gastrostomy tubes were placed in $2(11 \%)$ of 18 patients before hospital discharge. Both had poor swallow coordination, with associated aspiration in 1 patient; neither had vocal fold paralysis (Table 2). There have been no early or late deaths among the 18 patients undergoing biventricular repair.

Compared with patients who had undergone a Norwood procedure, patients undergoing biventricular repair had somewhat higher incidences of left true vocal fold paralysis, 
aspiration, and an abnormal MBS result. However, none of these differences was statistically significant (Figure 1).

\section{Time Course of Laryngopharyngeal Dysfunction}

Vocal fold paralysis tended to persist over time. Among the 7 patients with vocal fold paralysis after either a Norwood procedure or biventricular repair, 4 of 7 have had follow-up laryngoscopy from 3 months to 1 year after the operation. There was no change in vocal fold paralysis in $3(75 \%)$ of 4 of these patients, and improvement was seen in 1 patient.

In contrast, aspiration tended to improve or resolve over time. Among the 14 patients with aspiration on initial MBS after either a Norwood procedure or biventricular repair, 13 of 14 had at least one subsequent MBS over a time period of 1 week to 1 year. The results of the most recent MBS were normal in $8(62 \%)$ of 13 patients, showed laryngeal penetration in $3(23 \%)$ of 13 patients, and showed trace aspiration in $2(15 \%)$ of 13 patients.

At the time of laryngoscopy, a weak cry was noted in 13 of the 49 patients examined after either a Norwood procedure or biventricular repair. A weak cry was noted in 5 of the 7 patients with vocal cord paralysis, a significant association $(P<.01$, Fisher exact test). A weak cry had a sensitivity for vocal cord paralysis of $83 \%$, a specificity of $80 \%$, and a predictive value of $38 \%$.

\section{Discussion}

The results of the Norwood procedure have improved considerably over the last decade. ${ }^{1-7}$ As operative mortality has decreased, increasing attention has been focused on other measures of outcome after surgical intervention. ${ }^{11,12}$ Feeding intolerance remains a common postoperative problem. Establishing adequate oral intake is generally the last clinical hurdle to be overcome before hospital discharge and is a major determinant of hospital length of stay. Because the Norwood procedure, like other operations on the aortic arch, involves mobilization of the recurrent laryngeal nerve, operative damage to the nerve is one potential source of postoperative swallowing dysfunction. For these reasons, we undertook fiberoptic laryngoscopy and MBS studies to examine the incidence and significance of postoperative recurrent laryngeal nerve and swallowing dysfunction.

This study shows that after a Norwood operation, recurrent laryngeal nerve injury is relatively uncommon and is not consistently associated with swallowing dysfunction. Postoperative laryngoscopy documented vocal fold paralysis in $3(9 \%)$ of 33 patients compared with $4(25 \%)$ of 16 patients after aortic arch reconstruction as part of a biventricular repair. Three of the 7 patients with vocal fold paralysis had aspiration on MBS, whereas the other 4 had intact swallowing function. None required gastrostomy tube placement. These findings are consistent with those of a previous study, which found aspiration in $23 \%$ of adults

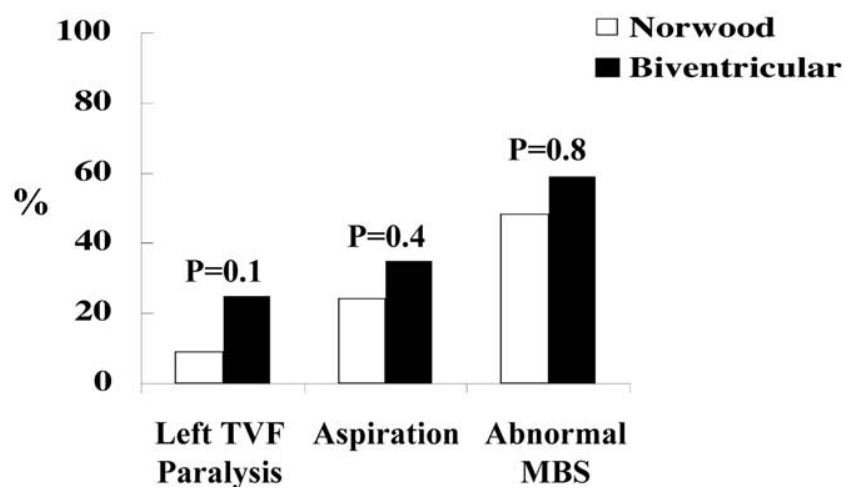

Figure 1. Incidence of laryngopharyngeal dysfunction: percentage of patients after the Norwood procedure versus biventricular repair. A, Left true vocal cord paralysis. B, Aspiration by modified barium swallow (MBS). C, Abnormal MBS. $P$ values are determined by using the $\chi^{2}$ test. TVF, True vocal fold.

with unilateral vocal fold immobility. ${ }^{8}$ Swallowing dysfunction in patients with recurrent nerve damage might be due to loss of pharyngeal innervation, glottic incompetence, and diminished cough impulse. ${ }^{9}$

We were unable to identify predictors of true vocal cord paralysis. Its cause is presumably intraoperative damage to the left recurrent laryngeal nerve along its course around the ductus arteriosus. Exposure of the descending aorta distal to any ductal tissue requires mobilization of the nerve, which might result in stretch injury. Although recurrent nerve injury was associated with a minority of the swallowing dysfunction observed in our study, avoiding damage to the nerve is clearly an important goal of the operative technique.

Postoperative vocal fold paralysis should generally be considered to be permanent: 4 of our 7 patients with nerve injury have undergone follow-up laryngoscopy, which showed persistence in 3 patients and improvement in 1 patient. This is consistent with a previous study, which found no improvement in 8 children with left vocal fold paralysis after thoracic surgery (primarily ligation of a patent ductus arteriosus) after an average follow-up of 6 months. ${ }^{13}$ It should be noted that the voice of an infant can improve despite persistence of vocal fold paralysis. This improvement is due to the plasticity of the glottis and the ability of the opposite vocal fold to compensate. We recommend periodic fiberoptic laryngoscopy until the infant is at least 18 months of age to determine whether an injury is permanent.

Another notable finding of postoperative laryngoscopy was a glottic gap, which was seen in 3 patients after a Norwood procedure. The 3 patients with a glottic gap all had aspiration on initial MBS. Two had gastrostomy tubes placed before hospital discharge. The third began oral feeding after a subsequent MBS showed resolution of aspiration 
and was the only study patient to die in the hospital. A glottic gap is often an indicator of generalized weakness. We regard the finding of a glottic gap as a high-risk marker and a strong indication for gastrostomy tube placement.

The current study shows that abnormalities of swallowing function are common after either a Norwood procedure or an aortic arch reconstruction as part of a biventricular repair. This finding indicates that swallowing dysfunction after a Norwood procedure is not simply caused by the hemodynamic burden of parallel pulmonary and systemic circulations. Although we were unable to identify predictors of swallowing dysfunction among our patients, its causes are likely multiple. Otherwise normal infants can have swallowing abnormalities, which include variability in suck and oral transit time, vallecular residuals after swallowing, and hesitation of bolus transit into the cervical esophagus. ${ }^{14}$ The pharyngeal stage of swallowing, which is controlled by the medulla oblongata, is not well developed in neonates and might contribute to these findings. ${ }^{15}$ Coordinated swallowing begins during fetal life and might require the initiation of oral feeding shortly after birth for maintenance and development ${ }^{9}$; a delay in oral feeding until extubation after a major operation might impair coordinated swallowing. Finally, swallowing is a complex process under both voluntary and involuntary control, so that factors that affect neurodevelopmental outcome might affect swallowing function. ${ }^{9,16}$ One such factor is the duration of intraoperative circulatory arrest. ${ }^{17}$ Our study patients had relatively short circulatory arrest times because of the use of regional lowflow perfusion. ${ }^{10}$ However, the neurologic effects of regional low-flow perfusion in neonates are currently unknown. Clarifying the cause of postoperative swallowing dysfunction requires further study.

Aspiration is one of the most serious abnormalities of swallowing function. In this study postoperative MBS showed aspiration in $24 \%$ of patients after a Norwood procedure and in $35 \%$ of patients after a biventricular repair. Aspiration in infants is frequently silent (not associated with coughing, gagging, or choking) and could be a hidden source of morbidity. ${ }^{15,18}$ Swallowing dysfunction and aspiration have been identified in $92 \%$ of infants with near-miss sudden infant death syndrome. ${ }^{15}$ Our management approach has included the avoidance of oral feeding in any patient with aspiration until a subsequent MBS has shown resolution. Patients with persistent aspiration have had a gastrostomy tube placed before discharge. A nasogastric tube, compared with a gastrostomy tube, might be more difficult to manage at home, might impair swallowing function and competence of the upper and lower esophageal sphincters, and might worsen gastroesophageal reflux. Among our study patients, postoperative aspiration generally resolved over time. However, the time course was variable, with resolution occurring from 1 week to 6 months after surgical intervention, indicating the importance of continued follow-up studies after hospital discharge.

Interstage mortality between hospital discharge after a Norwood procedure and second-stage palliation has been reported in $7 \%$ to $24 \%$ of patients. ${ }^{3,19-21}$ Interstage death can occur near the time of feeding or be associated with feeding difficulties, ${ }^{22}$ raising the possibility that swallowing dysfunction is a contributing factor in some cases. Ghanayem and colleagues $^{22}$ showed a significant decrease in interstage mortality after the institution of a home monitoring program, which targets patient weight gain and oxygen saturation. Both of these target variables can be affected by feeding intolerance and silent aspiration. In the current study there was 1 sudden interstage death among the $32(3 \%)$ patients discharged after a Norwood procedure compared with $6(15 \%)$ among the 40 patients discharged before the institution of laryngopharyngeal function evaluation. Routine assessment for swallowing dysfunction and appropriate tailoring of feedings might decrease interstage mortality.

In the current study we found a higher incidence of postoperative swallowing dysfunction than previously reported in adults or older children. Swallowing dysfunction occurs in $3 \%$ to $4 \%$ of adults after cardiac surgery. ${ }^{16,23} \mathrm{Kohr}$ and associates ${ }^{24}$ identified dysphagia in $9(18 \%)$ of 50 children undergoing a variety of cardiac operations at a mean age of 4.8 years. Risk factors for dysphagia included age less than 3 years, preoperative intubation, and use of a transesophageal echocardiographic probe in patients weighing less than $5.5 \mathrm{~kg}$. The 3 patients who underwent a Norwood procedure all had postoperative swallowing dysfunction and were discharged with nasogastric tube feedings. ${ }^{24}$

The current study has several limitations. No patient underwent preoperative laryngoscopy or MBS. This was not generally possible in prostaglandin-dependent neonates in an intensive care unit, many of whom were intubated. Follow-up laryngoscopy and MBS were not consistently performed in all patients with abnormalities. Gastroesophageal reflux, which can be associated with aspiration and swallowing dysfunction, ${ }^{15}$ was not routinely studied. Finally, routine evaluation of laryngopharyngeal function has been part of a management approach that has resulted in low hospital and interstage mortality for the Norwood procedure. However, this evaluation strategy was introduced over the same time period as other changes in management, including the use of a right ventricle-to-pulmonary artery shunt. This makes it difficult to conclude that laryngopharyngeal function evaluation independently improves outcomes.

In summary, swallowing dysfunction occurs commonly after a Norwood procedure, being seen in $48 \%$ of patients, with aspiration in $24 \%$. Patients with swallowing dysfunction have an increased length of hospital stay. Recurrent laryngeal nerve injury is seen in $9 \%$ of patients and is a 
relatively uncommon cause of swallowing dysfunction. Both recurrent nerve injury and swallowing dysfunction occur at similar rates in patients undergoing a Norwood procedure and aortic arch reconstruction as part of a biventricular repair. Postoperative aspiration generally resolves over time, whereas vocal fold paralysis does not. Systematic evaluation of swallowing function allows appropriate tailoring of feeding regimens and placement of gastrostomy tubes and might contribute to decreased hospital and interstage mortality.

\section{References}

1. Tweddell JS, Hoffman GM, Mussatto KA, et al. Improved survival of patients undergoing palliation of hypoplastic left heart syndrome: lessons learned from 115 consecutive patients. Circulation. 2002; 106(suppl I):I82-9.

2. Mahle WT, Spray TL, Wernovsky G, Gaynor JW, Clark BJ III. Survival after reconstructive surgery for hypoplastic left heart syndrome; a 15-year experience from a single institution. Circulation. 2000;102(suppl III):III136-41.

3. Ashburn DA, McCrindle BW, Tchervenkov CI, et al. Outcomes after the Norwood operation in neonates with critical aortic stenosis or aortic valve atresia. J Thorac Cardiovasc Surg. 2003;125:1070-82.

4. Bove EL. Surgical treatment for hypoplastic left heart syndrome. Jpn J Thorac Cardiovasc Surg. 1999;47:47-56.

5. Tabbutt S, Dominguez T, Ravishankar C, et al. Contemporary comparison of outcomes following the use of the right ventricular to pulmonary artery conduit vs. the modified Blalock-Taussig shunt as part of the modified Norwood procedure. Presented at: the 41st Annual Meeting of the Society of Thoracic Surgeons; Tampa (FL): January 2005.

6. Cua CL, Thiagarajan RR, Lai L, et al. Single-ventricle palliation with right ventricle to pulmonary artery conduit: early outcomes and ICU course compared with the traditional Norwood operation. Circulation. 2004;110:III621-2.

7. Bradley SM, Simsic JM, McQuinn TC, Habib DM, Shirali GS, Atz AM. Hemodynamic status following the Norwood procedure: a comparison of right ventricle to pulmonary artery versus modified BlalockTaussig shunt. Ann Thorac Surg. 2004;78:933-41.

8. Bhattacharyya N, Kotz T, Shapiro J. Dysphagia and aspiration with unilateral vocal cord immobility: incidence, characterization, and response to surgical treatment. Ann Otol Rhinol Laryngol. 2002;111: 672-9.

9. Derkay CS, Schechter GL. Anatomy and physiology of pediatric swallowing disorders. Otolaryngol Clin North Am. 1998;31:397-404.

10. Pigula FA, Nemoto EM, Griffith BP, Siewers RD. Regional low-flow perfusion provides cerebral circulatory support during neonatal aortic arch reconstruction. J Thorac Cardiovasc Surg. 2000;119:331-9.

11. Mahle WT, Clancy RR, Moss EM, Gerdes M, Jobes DR, Wernovsky G. Neurodevelopmental outcome and lifestyle assessment in schoolaged and adolescent children with hypoplastic left heart syndrome. Pediatrics. 2000;105:1082-9.

12. Goldberg CS, Schwartz EM, Brunberg JA, et al. Neurodevelopmental outcome of patients after the Fontan operation: a comparison between children with hypoplastic left heart syndrome and other functional single ventricle lesions. J Pediatr. 2000;137:646-52.

13. Zbar RI, Smith RJ. Vocal fold paralysis in infants twelve months of age and younger. Otolaryngol Head Neck Surg. 1996;114:18-21.

14. Newman LA, Cleveland RH, Blickman JG, Hillman RE, Jaramillo D. Videofluoroscopic analysis of the infant swallow. Invest Radiol. 1991; 26:870-3.

15. Khoda E, Hisazumi H, Hirmatsu K. Swallowing dysfunction and aspiration in neonates and infants. Acta Otolaryngol (Suppl). 1994; 517:11-16.

16. Ferraris VA, Ferraris SP, Moritz DM, Welch S. Oropharyngeal dysphagia after cardiac operations. Ann Thorac Surg. 2001;71:1792-6.
17. Wypij D, Newburger JW, Rappaport LA, et al. The effect of duration of deep hypothermic circulatory arrest in infant heart surgery on late neurodevelopment: the Boston Circulatory Arrest Trial. J Thorac Cardiovasc Surg. 2003;126:1397-403.

18. Newman LA, Keckley C, Peteren MC, Hammer A. Swallowing function and medical diagnosis in infants suspected of dysphagia. Pediatrics. 2001;108:e106.

19. Pizarro C, Mroczek T, Malec E, Norwood WI. Right ventricle to pulmonary artery conduit reduces interim mortality after stage 1 Norwood for hypoplastic left heart syndrome. Ann Thorac Surg. 2004;78: 1959-64.

20. Fenton KN, Siewers RD, Rebovich B, Pigula FA. Interim mortality in infants with systemic-to-pulmonary artery shunts. Ann Thorac Surg. 2003;76:152-6.

21. Simsic JM, Atz AM, Stroud MR, Bradley SM. Risk factors for interstage death after the Norwood procedure. Pediatr Cardiol. Online first. Nov 5, 2004. DOI: 10.1007/s00246-004-0776-4.

22. Ghanayem NS, Hoffman GM, Mussatto KA, et al. Home surveillance program prevents interstage mortality after the Norwood procedure. J Thorac Cardiovasc Surg. 2003;126:1367-75.

23. Hogue CW, Lappas GD, Creswell LL, et al. Swallowing dysfunction after cardiac operations. J Thorac Cardiovasc Surg. 1995;110:517-22.

24. Kohr LM, Dargan M, Hague A, et al. The incidence of dysphagia in pediatric patients after open heart procedures with transesophageal echocardiography. Ann Thorac Surg. 2003;76:1450-6.

\section{Discussion}

Dr James S. Tweddell (Milwaukee, Wis). That was an excellent presentation, Dr Skinner. I quite agree with your statement in the "Discussion" section that establishing adequate oral intake is the last clinical hurdle to be overcome before hospital discharge and is the major determinant of hospital stay. Indeed, this can be a period of intense frustration for the families.

Furthermore, we would strongly agree with one of your conclusions that it is unacceptable to discharge neonates and young infants with high-risk cardiac lesions with nasogastric tube feedings.

The strength of this study is the consistent management in that all survivors underwent laryngoscopy and modified barium swallow. This provides a broad picture of the problems with establishing oral intake in the postoperative period.

You appear to have ruled out recurrent laryngeal nerve injury as a cause of feeding problems, and therefore I wonder whether you would comment on the use of selective laryngoscopy for only those patients in whom you suspect a recurrent laryngeal nerve injury rather than routine laryngoscopy.

Dr Skinner. We would discourage the use of selective laryngoscopy because a weak cry or observation of an infant does not consistently give an indication of whether the infant has a functional left vocal fold. The infant larynx is extremely plastic and is often able to compensate for vocal fold paralysis. Among our study patients, the predictive value of a weak cry for vocal fold paralysis was only $38 \%$. However, vocal fold paralysis is an important finding for the patient's future. As more congenital heart babies grow into adulthood, they are at risk to their right recurrent laryngeal nerve from viral illnesses, subclavian lines, thyroid surgery, or carotid surgery, and it is very important to know the status of their vocal fold function.

Dr Tweddell. Recurrent laryngeal nerve injury was nicely demonstrated in the videos and occurred in only $9 \%$ of the patients in your study, which is commendable, but there were also some other abnormal laryngoscopic findings. To what do you attribute the abnormal findings of glottic gap and vocal cord dyskinesia? Could these additional findings, which occurred in 4 patients- 
glottic gap in 3 and vocal cord dyskinesia in 1-be evidence of lesser degrees of left recurrent nerve injury?

Dr Skinner. Generally we find that a glottic gap is associated with generalized patient weakness and not with a recurrent laryngeal nerve injury. With a glottic gap, we see bowing of both vocal cords and not simply the left vocal cord. We believe that this is a significant finding because all 3 of our patients with a glottic gap showed aspiration. Whether this is a sign of a global neurologic process or specific swallow discoordination remains to be elucidated.

Regarding some of the other laryngoscopic findings-some granulation tissue or evidence of reflux-when those were seen, we find those significant because they can trigger apneic or vagal reflux as well, and we recommend full workup for gastroesophageal reflux in those infants.

Dr Tweddell. Did glottic gap resolve then?

Dr Skinner. Only one of the 3 patients with a glottic gap underwent repeat laryngoscopy; the glottic gap resolved in this patient.

Dr Tweddell. I note in the article, which was very well written, that abnormalities identified on the modified barium swallow improved over time, and this is in contrast to recurrent nerve injury, which did not appear to improve often. How long did it takeI noticed in one patient it took 6 months-but typically how long would you wait to expect to find normalization of the modified barium swallow?

Dr Skinner. Our protocol starts with an initial swallow, preferably before the child starts oral intake. If we see an abnormality, that study is repeated within a week's time, with subsequent studies being dictated by the findings. Among the study patients, the time course of improvement was quite variable, with improvement occurring from 1 week up to 1 year after surgical intervention.

Dr Tweddell. Having ruled out recurrent nerve injury as a major cause of feeding problems in this group of patients, would you care to speculate on just what the causes of inadequate oral feeding might be?

Dr Skinner. I do not think anybody really knows the answer to that yet. One suggestion is a global hypoxic insult. We did not see any evidence of that in our study because we did not find any relationship between operative times and laryngopharyngeal dysfunction. The relationship among neurodevelopmental outcome, genetic syndromes, and swallowing dysfunction is something that certainly merits further investigation.

Dr Tweddell. The point of evaluating laryngopharyngeal function is 2-fold: (1) to decrease the risk of aspiration with the potential for sudden death and (2) to ensure growth and development to achieve successful subsequent palliation. In our experience gastrostomy tubes were used in up to $35 \%$ of patients, primarily for an inability to achieve adequate oral intake. That is a different end point than in your study. Do you have a sense as to whether the patients with laryngeal nerve injury without a gastrostomy tube are achieving growth as well as patients without a recurrent laryngeal nerve injury?

Dr Skinner. So those with recurrent laryngeal nerve injury?

Dr Tweddell. Those patients with a recurrent nerve injury that you are managing without a gastrostomy tube, are they growing?

Dr Skinner. We have not specifically looked at weight gain over time in these patients.
Dr Tweddell. Were any of your patients able to breast-feed successfully?

Dr Skinner. Yes.

Dr Tweddell. How many?

Dr Skinner. Of the number that went home without either gastrostomy, which was 6 , or thickened feedings, which was 2 , for the remaining 24 patients, it was by parental choice whether they were breast-fed or bottle fed. A minority of them were breast-fed.

Dr Tweddell. Okay. But some of them were able to breast-feed exclusively?

Dr Skinner. Yes.

Dr Tweddell. I want to thank you. Your presentation was excellent. I congratulate you and your team.

Dr Serafin Y. DeLeon (New Orleans, La). That was a nice and elegant presentation. However, I think the title should have been a little bit different. It looks like it should be "Recurrent laryngeal nerve injury in aortic arch reconstruction." And the focus of this study should have been: if it happens, what to do about it, but most importantly, how to avoid it.

It seems like there is a high incidence of recurrent laryngeal nerve injury in both groups of patients, and I think a lot of it should be preventable.

Dr Skinner. I think the surgical technique is one of the things to look at, and I know it is of great concern among the thoracic surgeons in the room to avoid any injury to the nerve. As we know from the otolaryngology literature, when operating in the neck, especially in the thyroid bed, there is some unavoidable injury, despite every effort that we make to protect the nerve. We would certainly be interested in any other reports on the incidence of recurrent nerve injury after neonatal aortic arch surgery.

Dr Emile A. Bacha (Chicago, Ill). I just had a quick observation that goes along with what you said that laryngopharyngeal dysfunction is part of a genetic problem and against the fact that this might be a surgical trauma, be it laryngeal nerve or brain injury during bypass.

In the series of hybrid procedures, which you probably are not familiar with, it is a non-cardiopulmonary bypass-based firststage palliation, and we found that the incidence of dysphasia is actually quite high. These are patients who have not had their arch surgery yet, and it is very high in those patients as well.

Dr Joseph J. Amato (Chicago, Ill). I was just wondering, rather than ascribe the blame to laryngeal nerve injury to the operation, was there any correlation to the size of the end tracheal tube or perhaps transesophageal echocardiographic probe? As you well know, compression from the inside can also cause laryngeal nerve injury. I have reviewed many articles in the literature reporting this. I personally have known of several instances of this happening. Was there any correlation in the studies of the size of the endotracheal tube or whether transesophageal echocardiography was done at the same time of the surgical intervention?

Dr Skinner. We do not have specific data regarding the size of the endotracheal tubes. A leak is checked for at the time of placement to guard against oversizing the endotracheal tube in the neonate's trachea. None of these patients underwent transesophageal echocardiography.

Dr Amato. But the compression of the balloon sometimes can cause injury, as you well know.

Dr Skinner. None of the endotracheal tubes were cuffed. 
Dr Jeffrey P. Jacobs (St Petersburg, Fla). First, I would like to congratulate you for an excellent presentation and for dealing so nicely with perhaps the longest line of questioners at the entire meeting.

I agree with Dr Tweddell when he said that he is reluctant to send infants after heart surgery home with a nasogastric feeding tube in place. I certainly share that reluctance. Is there is any situation in which you would recommend sending a baby home with a nasogastric feeding tube, rather than sending a baby home with a gastrostomy?

Dr Skinner. Generally, no. There are a number of reasons why we would prefer to send a patient home with a gastrostomy tube rather than a nasogastric tube. A nasogastric tube is easily dislodged or pulled out. It is generally easier for the parents to manage a gastrostomy tube than a nasogastric tube. Furthermore, nasogastric tubes in and of themselves might be associated with swallowing dysfunction and residual patency of the upper and lower esophageal sphincters, which can cause gastroesophageal reflux and apneic events.

Dr Carl L. Backer (Chicago, Ill). Let me just follow up on that. Maybe we could have a show of hands.

How many in the audience would send a baby home after a Norwood procedure with a nasogastric tube in place for feeding? (Show of hands.)

And how many would only send them home with a gastrostomy? (Show of hands.)

It looks like it is about $40 \%$ for a nasogastric tube and about $60 \%$ for a gastrostomy.

Dr Skinner, that was a very nice presentation with a great discussion.

Access to The Journal of Thoracic and Cardiovascular Surgery Online is reserved for print subscribers!

Full-text access to The Journal of Thoracic and Cardiovascular Surgery Online is available for all print subscribers. To activate your individual online subscription, please visit The Journal of Thoracic and Cardiovascular Surgery Online, point your browser to http://www.mosby.com/jtcvs, follow the prompts to activate your online access, and follow the instructions. To activate your account, you will need your subscriber account number, which you can find on your mailing label (note: the number of digits in your subscriber account number varies from 6 to 10). See the example below in which the subscriber account number has been circled:

\section{Sample mailing label}

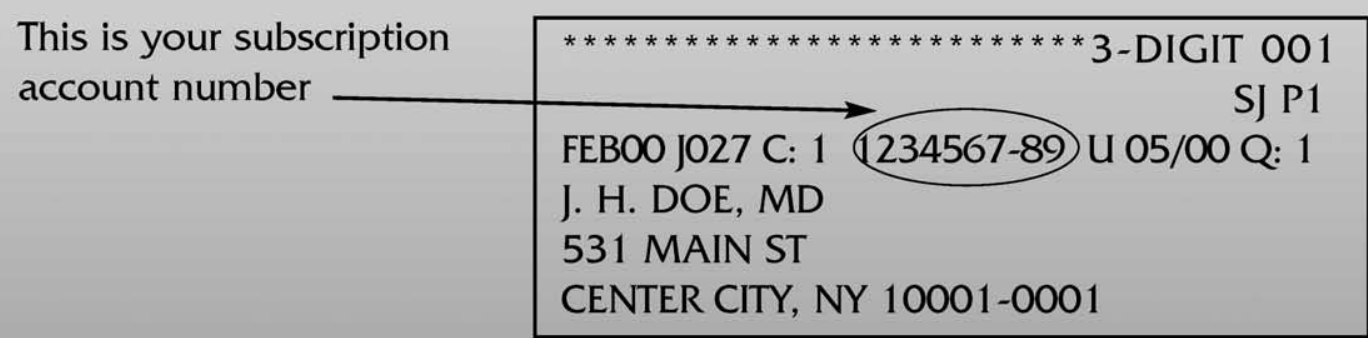

Personal subscriptions to The Journal of Thoracic and Cardiovascular Surgery Online are for individual use only and may not be transferred. Use of The Journal of Thoracic and Cardiovascular Surgery Online is subject to agreement to the terms and conditions as indicated online. 